\title{
Thrombolysis Outcomes in Patients with Diabetes and Previous Stroke: A Meta-Analysis
}

\author{
Azalea T. Pajo (D), Jose Danilo B. Diestro (D), Adrian I. Espiritu (iD, \\ Adam A. Dmytriw (D), Alejandro Enriquez-Marulanda, Robert Joseph C. Sarmiento, \\ Marjorie Anne C. Bagnas, Julian Spears, Maria Cristina Z. San Jose
}

\begin{abstract}
Background: Intravenous tissue-type plasminogen activator (IVtPA) is a proven treatment for acute ischemic stroke; however, diabetes mellitus (DM) and previous cerebral infarction (PCI) were considered relative contraindications for thrombolysis within the 3-4.5 h period. Objective: The study aimed to determine the safety and efficacy of IVtPA among diabetic patients with PCI presenting with acute ischemic stroke. Methods: Studies which evaluated the outcome of IVtPA in terms of symptomatic intracerebral hemorrhage (sICH), functional outcome in modified Rankin scale, and death among diabetic patients with PCI presenting with acute ischemic stroke within the 3-4.5 h period were systematically searched until July 2019 . Screening and eligibility criteria were applied. Risk of bias was evaluated using the Newcastle-Ottawa Scale. Odds ratios (ORs) with 95\% confidence interval (CI) were used to compare measures of treatment effect. Mantel-Haenszel method and random-effects model were also employed. Results: Four registry-based studies with a total of 44,572 patients were included for quantitative synthesis. Giving IVtPA among DM+/PCI+ patients did not result in significantly increased rate of sICH $(\mathrm{OR}, 1.09 ; 95 \% \mathrm{CI}, 0.88,1.36)$ compared to No DM+/PCI+ patients. However, there was significantly higher mortality (OR, 1.81; 95\% CI, 1.60, 2.06) in the DM+/PCI+ group. Conversely, among those who survived, the $\mathrm{DM}+/ \mathrm{PCI}+$ patients were more functionally independent at 3 months (OR, 0.76; 95\% CI, 0.61, 0.94). Conclusion: Limited evidence suggests that thrombolysis in DM+/PCI+ patients does not result in significantly higher incidence of sICH and may improve functional independence. However, the significantly higher mortality in this group warrants an assessment of the individualized risk-benefit ratio in the use of IVtPA.
\end{abstract}

RÉSUMÉ: Méta-analyse des résultats d'un traitement thrombolytique administré à des patients diabétiques ayant des antécédents d'infarctus cérébraux. Contexte : L'altéplase par voie intraveineuse (tPA-IV) est un traitement pour les AVC ischémiques aigus qui a fait ses preuves. Cela dit, le fait de souffrir de diabète sucré (DS) et d'avoir été victime dans le passé d'un infarctus cérébral continuent, dans des délais allant de 3 à 4,5 heures, à être considérés comme des contre-indications relatives pour un traitement thrombolytique. Objectif : Cette étude a cherché à démontrer la sécurité et l'efficacité du tPA-IV chez des patients diabétiques avec des antécédents d'infarctus cérébraux victimes d'un AVC ischémique aigu. Méthodes : Pour les patients décrits précédemment et tenant compte de délais de 3 à 4,5 heures, nous avons effectué une recherche systématique au sujet d'études évaluant l'efficacité du tPA-IV en lien avec de potentielles manifestations d'hémorragie intracérébrale symptomatique, des résultats fonctionnels à l'échelle modifiée de Rankin et des taux de mortalité. En plus de nous limiter à des études parues avant juillet 2019, nous avons mis de l'avant des critères de filtrage et d'admissibilité. Les risques de biais ont été évalués au moyen de l'échelle de Newcastle-Ottawa. Les rapports des cotes (RC) avec un intervalle de confiance (IC) de $95 \%$ ont été par ailleurs utilisés pour comparer entre elles les mesures de l'effet du traitement. Finalement, la méthode de Mantel-Haenszel ainsi qu'un modèle à effets aléatoires ont été également appelés en renfort. Résultats : Au total, 4 études portant sur 44572 dossiers de patients ont été inclues en vue d'une synthèse quantitative. Le fait d'administrer du tPA-IV aux patients décrits ci-dessus n'a pas entraîné une augmentation significative du taux d'hémorragie intracérébrale symptomatique (RC 1,09; IC $95 \%$ : 0,88 - 1,36) en comparaison avec des patients non-diabétiques n'ayant pas d'antécédents d'infarctus cérébraux. Toutefois, les taux de mortalité se sont avérés nettement plus élevés (RC 1,81; IC 95\%: 1,60 - 2,06) parmi les patients qui nous intéressent ici. À l'inverse, parmi les patients ayant survécu, ceux qui avaient des antécédents d'infarctus cérébraux et qui étaient diabétiques se sont révélés au bout de 3 mois plus autonomes sur le plan fonctionnel (RC 0,76; IC $95 \%$ : 0,61- 0,94). Conclusion : Pour l'instant, des preuves limitées suggèrent qu'un traitement thrombolytique chez des patients diabétiques ayant des antécédents d'infarctus cérébraux n'entraîne pas une fréquence significativement plus élevée d'hémorragie intracérébrale symptomatique et pourrait améliorer en bout de ligne

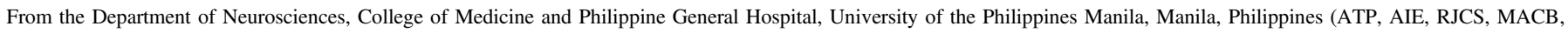

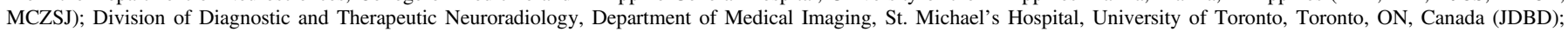

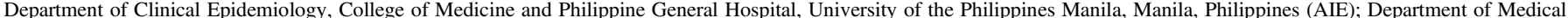

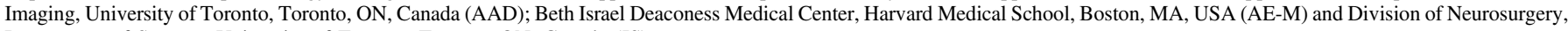
Department of Surgery, University of Toronto, Toronto, ON, Canada (JS)

Received February 10, 2020. Final Revisions Submitted March 19, 2020. Date of Acceptance March 22, 2020.

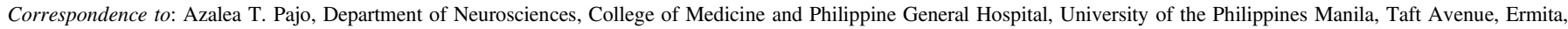
Manila 1000, Philippines. Email: atpajo@up.edu.ph or azaleapajo@gmail.com 
l'autonomie fonctionnelle des patients. Cela dit, le taux de mortalité nettement plus élevé au sein de ce groupe de patients justifie une évaluation du rapport risque-bénéfice individualisé rattaché au tPA-IV.

Keywords: Diabetes mellitus, Previous stroke, Previous cerebral infarction, IV thrombolysis, IVtPA, Outcome

doi:10.1017/cjn.2020.63

Can J Neurol Sci. 2020; 47: 486-493

\section{INTRODUCTION}

Worldwide, stroke is the second leading cause of death and a major cause of disability. ${ }^{1}$ Since the National Institute of Neurological Disorders and Stroke (NINDS) Intravenous alteplase to Intravenous tissue-type plasminogen activator (IVtPA) trial in 1995, a paradigm shift was initiated in the management of ischemic stroke. ${ }^{2,3}$ Timely administration of the drug effected better 90-day outcomes in carefully selected acute ischemic stroke patients. ${ }^{4}$ However, not all potentially eligible patients benefited from this form of treatment. ${ }^{5}$ Globally, only about $2 \%-$ $10 \%$ of stroke patients received IVtPA. ${ }^{5,6}$ Many patients failed to receive IVtPA on account of rigid guidelines that accompany the administration of the drug. ${ }^{7}$ Because of the criteria set by the landmark trial of the third European Cooperative Acute Stroke Study (ECASS III), patients with previous cerebral infarction (PCI) and diabetes mellitus (DM) were excluded in the $3-4.5 \mathrm{~h}$ extended time window. ${ }^{8}$ The exclusion is based on the poorer outcomes observed in patients with DM and PCI compared with those patients who have neither comorbidities. ${ }^{6,9-16}$ Recently published systematic review on early recurrent stroke and IVtPA, however, has shown similar findings in terms of functional outcome and symptomatic intracerebral hemorrhage (sICH) to that of published data on thrombolyzed patients without a recent stroke. ${ }^{17,18}$ Independently, secondary analyses of trial data and observational studies have identified hyperglycemia or DM as a risk factor for sICH after thrombolytic therapy, as well as in untreated stroke. ${ }^{19}$ Poorer response to IVtPA in these patients is considered to be a result of increased plasminogen activator inhibitor-1 activity, resistance to antithrombotic agents, and higher prevalence of atherosclerosis. ${ }^{11,20,21}$ Moreover, hyperglycemia has repeatedly shown a deleterious effect of exacerbating ischemic brain injury, accelerating the molecular processes leading to cell death, and resulting finally in larger infarct volumes and poorer outcomes, including higher mortality, poorer neurological and functional outcomes, longer hospital stay, higher readmission rates, and stroke recurrence. ${ }^{9,22}$ This can be explained from a pathophysiologic perspective, wherein excess perfusion after recanalization of local vascular occlusion as well as various mechanisms and factors involved in ischemic/ reperfusion cascade leads to the damage of the blood-brain barrier and dysfunction of the vascular basal lamina, which may cause intracerebral hemorrhage (ICH). ${ }^{23}$ Therefore, the exclusion criteria in previous studies and clinical practice may infer that the damage of blood-brain barrier and vascular basal lamina caused by previous infarction have not yet fully recovered; hence, intravenous thrombolysis with IVtPA may increase the risk for hemorrhage in these areas. ${ }^{23}$

Regardless, contraindications to IVtPA vary among guidelines such as the American Heart Association (AHA) guidelines ${ }^{24}$ and the European Stroke Initiative recommendations. ${ }^{13}$ The latest AHA/American Stroke Association (ASA) guidelines state that
IVtPA in patients with a combined history of DM and PCI presenting in the 3-4.5 $\mathrm{h}$ time window, IVtPA may be as effective as treatment in the 0 - to $3 \mathrm{~h}$ window. ${ }^{24}$ Despite increasing data supporting the benefit of IVtPA in these patients, the European restriction of IVtPA in patients with previous stroke and DM is still enforced. ${ }^{13,25}$

This review aims to determine the safety and efficacy of IVtPA among diabetic patients with a history of stroke presenting in the 3-4.5 h time window using meta-analysis of relevant studies in terms of the following outcome measures: mortality, symptomatic intracranial hemorrhage (sICH), and functional outcomes using modified Rankin scale (mRS).

\section{Methods}

The Preferred Reporting Items for Systematic Reviews and Meta-analysis (PRISMA) and the Meta-analysis of Observational Studies in Epidemiology (MOOSE) Consensus Statements guidelines were followed in this review. ${ }^{26,27}$

\section{Criteria for Inclusion of Studies}

Types of Studies. We considered studies that employed randomized controlled trials and prospective or retrospective cohort studies. Studies that were designed with no comparator group were excluded. Only studies that reported primary data, expressed in the English language and available in full-text, were considered.

Types of Participants. Studies whose participants were selected according to the NINDS trial criteria in the administration of IVtPA were considered in this review. ${ }^{3}$ We included in the analyses the following patients who presented with a new acute ischemic stroke within 3-4.5 h time window and underwent IVtPA: (1) diabetic patients with PCI (DM+/PCI+) and (2) patients with no diabetes and $\mathrm{PCI}(\mathrm{No} \mathrm{DM}+/ \mathrm{PCI}+)$. $\mathrm{PCI}$ is defined as having a history of previous ischemic stroke in the last 3 months. The No DM+/PCI+ group includes patients with neither DM nor PCI, patients with DM only, and patients with PCI only.

Types of Interventions. We included studies which employed the standard $0.9 \mathrm{mg} / \mathrm{kg}$ dose of IVtPA within $3-4.5 \mathrm{~h}$ time window of stroke onset.

Types of Outcome Measures. The primary outcomes considered in this review are the safety endpoints of IVtPA measured in terms of mortality and sICH as defined by the Safe Implementation of Thrombolysis in Stroke-Monitoring Study (SITS-MOST) criteria. ${ }^{9}$ The secondary endpoint considered in this review is the efficacy outcome of IVtPA on functional outcomes as measured by $\mathrm{mRS}$ at 3 months. A good functional outcome was variably defined as $\mathrm{mRS}$ of $0-2$ indicating functional independence, while all others were considered poor outcome.

\section{Search Methods for Identification of Studies}

Literature search was done up to July 19, 2019, in the following databases: Medline via PubMed, ClinicalTrials.gov 


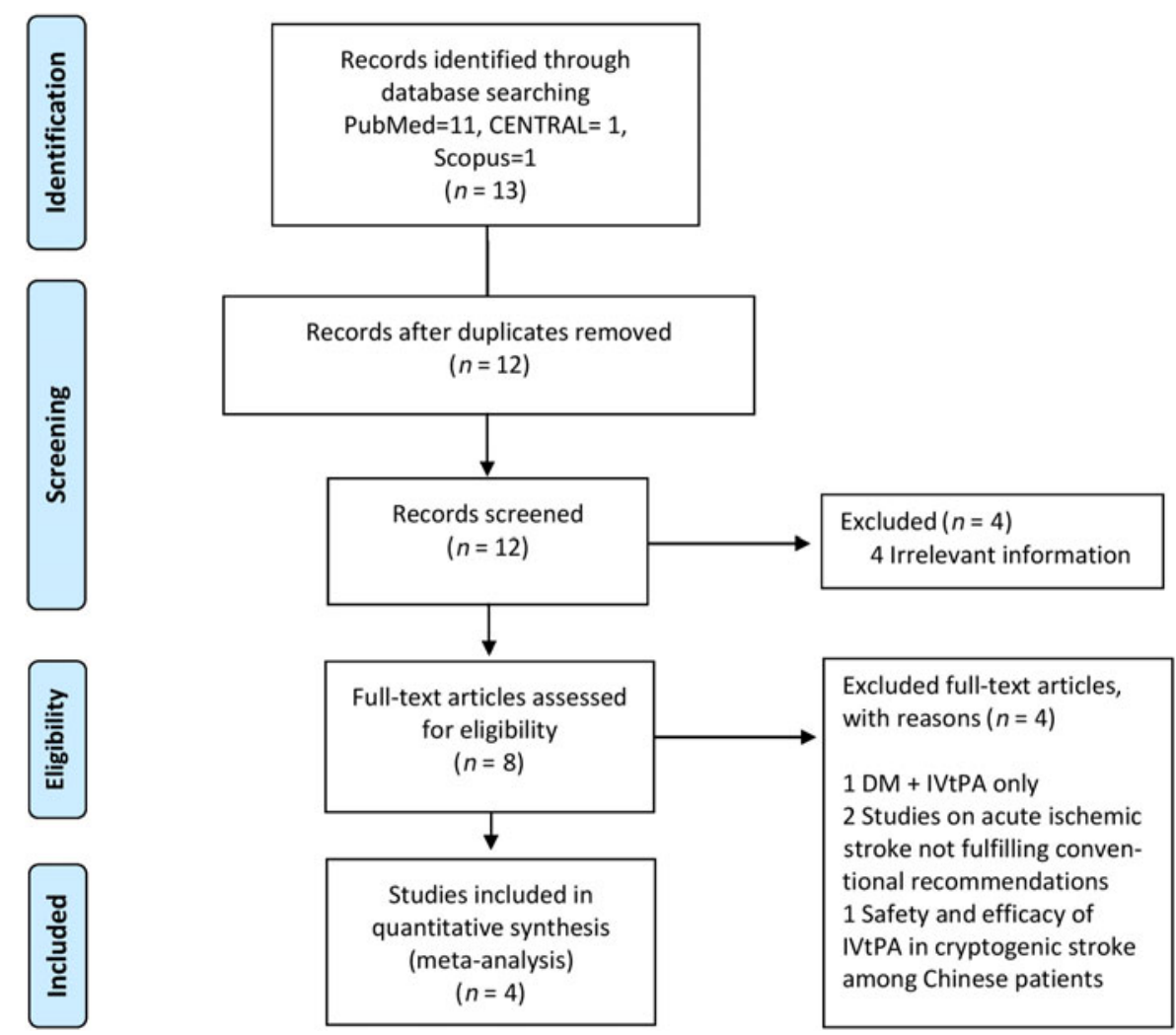

Figure 1: PRISMA flow diagram for study selection.

website, Cochrane Central Register for Controlled Trials (CENTRAL) by the Cochrane Library, and Scopus. The following general search and corresponding MeSH terms were used: "diabetes mellitus," "previous stroke," and "intravenous thrombolysis." Alternate keywords such as "DM," "previous cerebral infarction," and "IV r-TPA" were also used. The detailed search strategies are listed in Appendix A.

\section{Selection of Studies}

Titles and abstracts obtained in the systematic search were evaluated using predefined screening criteria by two authors (ATP, AIE). After deduplication, full-text of articles which passed the screening criteria were obtained and evaluated by two authors (JDD, AIE). Studies which fulfilled the eligibility criteria were included in this review. Two authors (ATP, AIE) collected relevant data from the included studies.

\section{Methodological Quality Assessment}

The methodological quality of the studies included was conducted by two authors (ATP, JDBD). The risk of bias was assessed using the Newcastle-Ottawa Scale. ${ }^{28}$

\section{Data Collection and Analysis}

Odds ratios (ORs) with $95 \%$ confidence interval (CI) were used to compare measures of treatment effect. The data were analyzed using Stata 15.1 software (StataCorp. 2017. Stata Statistical Software: Release 15. College Station, TX: StataCorp LLC). Dichotomous outcomes were pooled using the Mantel-Haenszel method. Random-effects model was used in the meta-analyses. ${ }^{29}$
Statistical significance was considered if the $95 \%$ CI of the OR between the intervention and the control arms did not include the number one.

Statistical heterogeneity was detected using the chi-squared test with a $p$-value $<0.10$ to indicate statistically significant heterogeneity. ${ }^{30}$ The $I^{2}$ statistic was employed to determine degree of heterogeneity, with an $I^{2}>50 \%$ denoting substantial heterogeneity. ${ }^{30}$

\section{ResUlTS}

\section{Systematic Literature Review}

Using the search terms, we identified a total of 13 records with only one duplicate removed (Figure 1). After applying the eligibility criteria, four papers were included in this review. ${ }^{31,32}$

\section{Characteristics of Studies and Patients}

The studies' and patients' characteristics are summarized in Appendix B and Table 1, respectively. All of the studies were registry based. Of the 44,572 patients in the combined registries, 2841 of them had both DM and PCI (DM+/PCI+), while 41,731 had DM only, PCI only, and neither DM nor PCI (No DM+/PCI+ group). Most of the patients were males ( $n=24,305 ; 54.5 \%)$. The great majority of the patients were in the No DM+/PCI+ group $(n=41,731 ; 93.6 \%)$. DM+/PCI+ patients were older than the No DM+/PCI+ group. Baseline NIHSS scores were similar in both groups except for the study by Filipov which showed higher NIHSS on admission for the DM+/PCI+ group. Higher admission blood glucose was recorded in $\mathrm{DM}+/ \mathrm{PCI}+$ patients. 
Table 1: Patient demographic and clinical characteristics

\begin{tabular}{|c|c|c|c|c|c|c|c|c|c|c|c|c|c|c|c|c|}
\hline & \multicolumn{4}{|c|}{ Fuentes et al. ${ }^{30}$} & \multicolumn{4}{|c|}{ Mishra et al. ${ }^{31}$} & \multicolumn{4}{|c|}{ Ehrlich et al. ${ }^{18}$} & \multicolumn{4}{|c|}{ Filipov et al. ${ }^{24}$} \\
\hline & $\begin{array}{l}\mathbf{D M}+/ \mathbf{P C I} \\
+(n=34) \\
\end{array}$ & $\begin{array}{c}\text { DM+/PCI- } \\
(n=257)\end{array}$ & $\begin{array}{c}\text { DM-/PCI } \\
+(n=118) \\
\end{array}$ & $\begin{array}{l}\text { DM-/PCI- } \\
(\mathrm{n}=1063)\end{array}$ & $\begin{array}{r}\text { DM+/PCI } \\
+(n=602) \\
\end{array}$ & $\begin{array}{l}\text { DM+/PCI- } \\
(n=3905)\end{array}$ & \begin{tabular}{|c|} 
DM-/PCI \\
$+(n=2972)$ \\
\end{tabular} & $\begin{array}{c}\text { DM-/PCI- } \\
(n=16275)\end{array}$ & $\begin{array}{l}\text { DM+/PCI } \\
+(\mathbf{n}=\mathbf{2 1 2 9}) \\
\end{array}$ & DM+/PCI- & DM-/PCI+ & $\begin{array}{l}\begin{array}{l}\text { DM-/PCI- } \\
(\mathbf{n}=16690)\end{array} \\
\end{array}$ & $\begin{array}{l}\text { DM+/PCI } \\
+(n=76) \\
\end{array}$ & DM+/PCI- & DM-/PCI+ & $\begin{array}{l}\text { DM-/PCI- } \\
(n=239)\end{array}$ \\
\hline Age, mean (SD), years & $73.1(7.1)$ & $71.1(10.7)$ & $70.2(12.1)$ & $66.8(13)$ & $71(9.4)$ & $69.9(9.5)$ & $70.1(10.5)$ & $65.9(13.1)$ & 69 (12.23) & N/A & N/A & $68(15.76)$ & $76.1(11.3)$ & N/A & N/A & $69.3(15.2)$ \\
\hline Gender (Female), $n(\%)$ & $12(35.3)$ & $122(47.3)$ & $56(47.1)$ & $501(47.1)$ & $239(39.7)$ & $1550(39.7)$ & 1224 (41.2) & $6865(42.2)$ & 1079 (50.7) & N/A & N/A & $8352(50.04)$ & $38(50)$ & N/A & N/A & $117(49)$ \\
\hline \multicolumn{17}{|l|}{ Medical history, $n(\%)$} \\
\hline Hypertension & $30(88.2)$ & $216(83.4)$ & $93(78.2)$ & $573(53.9)$ & $538(89.7)$ & 3235 (83.4) & $2247(76.5)$ & 8918 (55.7) & $1868(87.74)$ & N/A & N/A & $10717(64.21)$ & $71(93.4)$ & N/A & N/A & $188(78.7)$ \\
\hline Atrial fibrillation & $9(26.5)$ & $62(23.9)$ & $33(27.7)$ & $167(15.7)$ & $179(30.3)$ & $1130(29.6)$ & 799 (27.6) & $3850(24.1)$ & $345(16.2)$ & N/A & N/A & $2761(16.54)$ & $30(36.8)$ & N/A & N/A & $62(25.9)$ \\
\hline Congestive heart failure & $4(11.8)$ & $26(10.0)$ & $15(12.6)$ & $60(5.6)$ & $92(15.8)$ & 538 (14.2) & $312(10.8)$ & $1108(6.9)$ & 14.51 & N/A & N/A & 6.43 & NA & N/A & N/A & NA \\
\hline Prior anti-platelet use & $16(47.1)$ & $63(24.3)$ & $60(50.4)$ & $170(16)$ & $442(77)$ & $1920(50.6)$ & $2140(74.7)$ & 4888 (30.6) & $1486(69.82)$ & N/A & N/A & $5816(34.85)$ & $54(71.1)$ & N/A & N/A & $84(35.1)$ \\
\hline \multicolumn{17}{|l|}{ Admission variables } \\
\hline $\begin{array}{l}\text { Arrival blood glucose, } \\
\text { mean }(\mathrm{mg} / \mathrm{dL})\end{array}$ & 145.5 & 173.1 & 117.7 & 120.4 & NA & NA & NA & NA & 160 & N/A & N/A & 112 & 152 & N/A & N/A & 116 \\
\hline $\begin{array}{l}\text { Systolic BP }(\mathrm{mmHg}) \text {, } \\
\text { median (SD) }\end{array}$ & $151.2(24)^{*}$ & $153.7(21.3)$ & $149.4(21.5)$ & $146.4(22.7)^{*}$ & $154(20.5)$ & $154.6(20.7)$ & $152.1(20.4)$ & $150.3(21.2)$ & $158(138-80)$ & N/A & N/A & 155 (137-176) & $163(28)$ & N/A & N/A & $166(32)$ \\
\hline Baseline NIHSS (median) & $13(11)$ & $13(11)$ & $12(11)$ & $13(10)$ & 12 & 13 & 12 & 12 & 8 & N/A & N/A & 7 & 7 & N/A & N/A & 5 \\
\hline
\end{tabular}

NR means not reported. *Only the mean is reported by Fuentes for the systolic blood pressure on admission. 


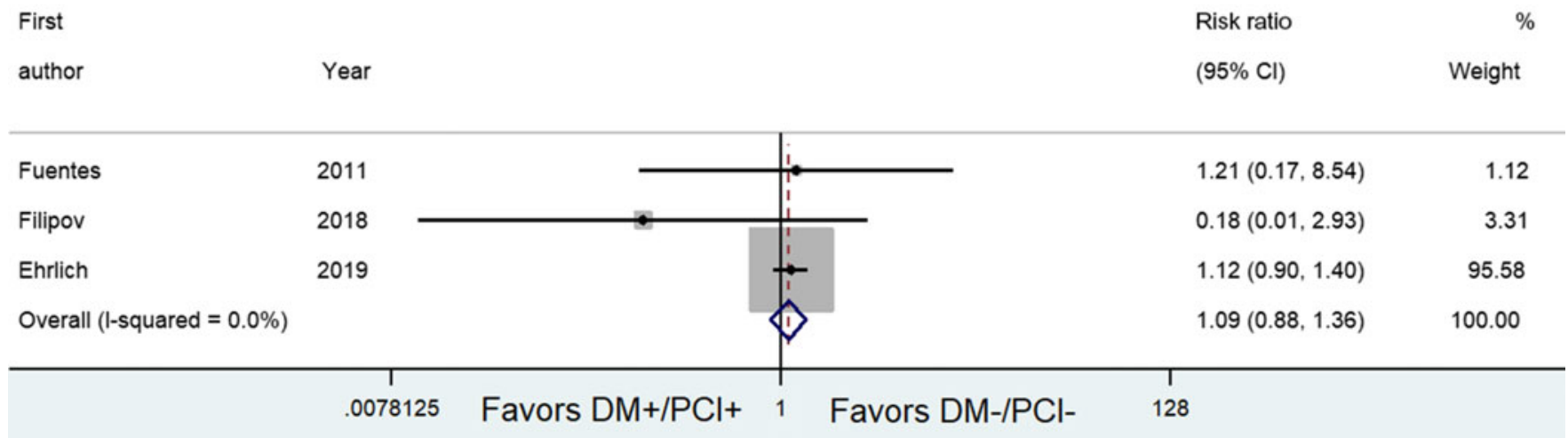

NOTE: Weights are from Mantel-Haenszel model; continuity correction applied to studies with zero cells

Figure 2: Forest plot showing odds ratios comparing the outcomes of diabetic patients with prior cerebral infarction (DM+/PCI+) versus patients with no diabetes and with no previous cerebral infarction (No DM+/PCI+) in terms of the risk of symptomatic intracranial hemorrhage.

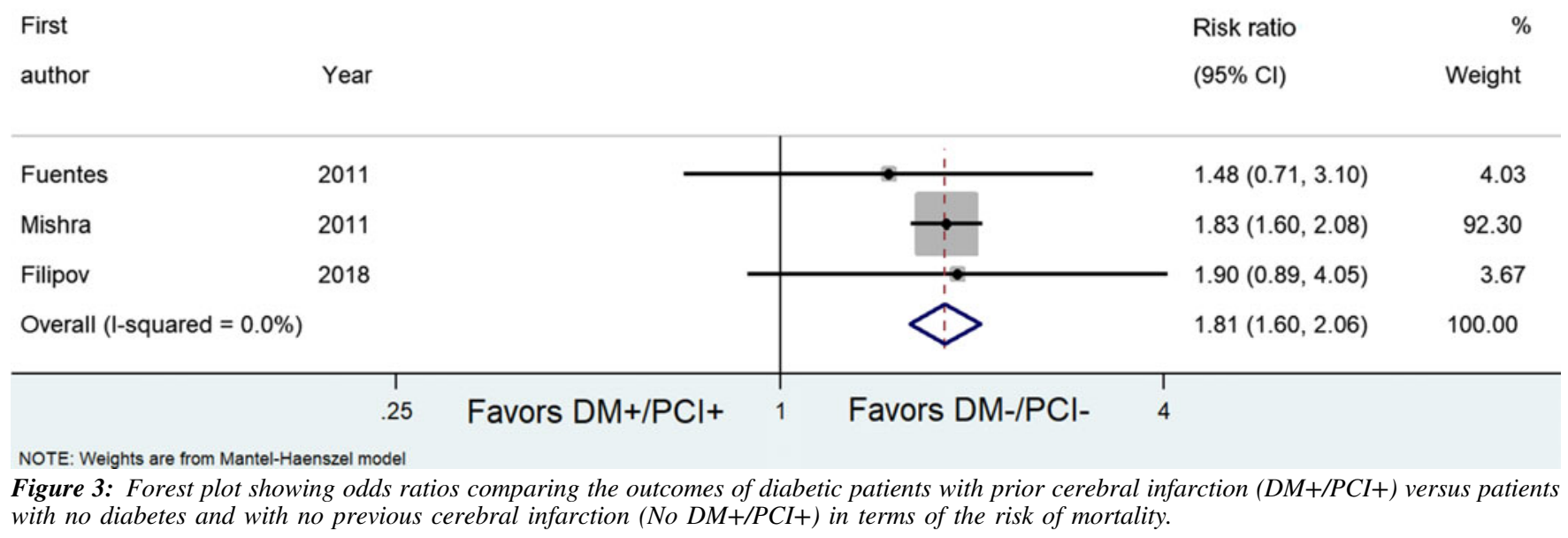

Furthermore, hypertension and atrial fibrillation are more common in the DM+/PCI+ group with note of higher number of antiplatelet use.

\section{Methodological Quality Assessment}

The results were summarized in a risk of bias table (see Appendix C).

\section{Outcomes}

Unadjusted rates of $\mathrm{sICH}$ were not increased significantly among DM+/PCI+ patients who were given IVtPA (OR, 1.09; $95 \%$ CI, 0.88, 1.36) (see Figure 2). ${ }^{19,25,31}$ However, mortality appears to be increased in the DM+/PCI+ group (OR, 1.81; $95 \%$ CI, 1.60, 2.06) (see Figure 3). ${ }^{25,31,32}$ In terms of functional outcome, IVtPA in DM+/PCI+ patients was more likely to be functionally independent at 3 months (mRS of 0-2) compared with the No DM+/PCI+ group (OR, 0.76; 95\% CI, 0.61, 0.94) (Figure 4). ${ }^{31,32}$

\section{Discussion}

Most of the contraindications to IVtPA were derived from major stroke trials as expert consensus in the field for the NINDS trial. ${ }^{7}$ The basis for the exclusion of DM, PCI, or both in the administration of IVtPA was due to the findings that associate these comorbidities to a higher risk of hemorrhagic transformation after IVtPA administration. ${ }^{13}$ Compared to patients who were given IVtPA according to SITS-MOST criteria, a previous report suggested that patients with DM and PCI showed significantly less neurological improvement, more sICH, and higher mortality at discharge. ${ }^{9}$

Contrary to these reports, using the 4 registries analyzed in this review, thrombolysis within the $3-4.5 \mathrm{~h}$ period post-ictus in DM $+/ \mathrm{PCI}+$ patients had no significant difference in terms of $\mathrm{sICH}$ compared to the No DM+/PCI+ group. DM+/PCI+ patients treated with IVtPA are more likely to be ambulatory at 3 months compared to the No DM+/PCI+ patients. However, higher mortality was observed after giving IVtPA in the DM+/PCI+ group compared to No DM+/PCI+ group. These results imply that despite having a higher likelihood of dying DM+/PCI+ patients who actually survive are less disabled than the patients in the No DM+/PCI+ group. However, we also note that the meta-analysis done for 3-month functional outcomes showed significant statistical heterogeneity at $51 \%$. In addition, the study of Filipov was not included in the meta-analysis for functional outcomes but was included in the mortality meta-analysis. ${ }^{25}$ 


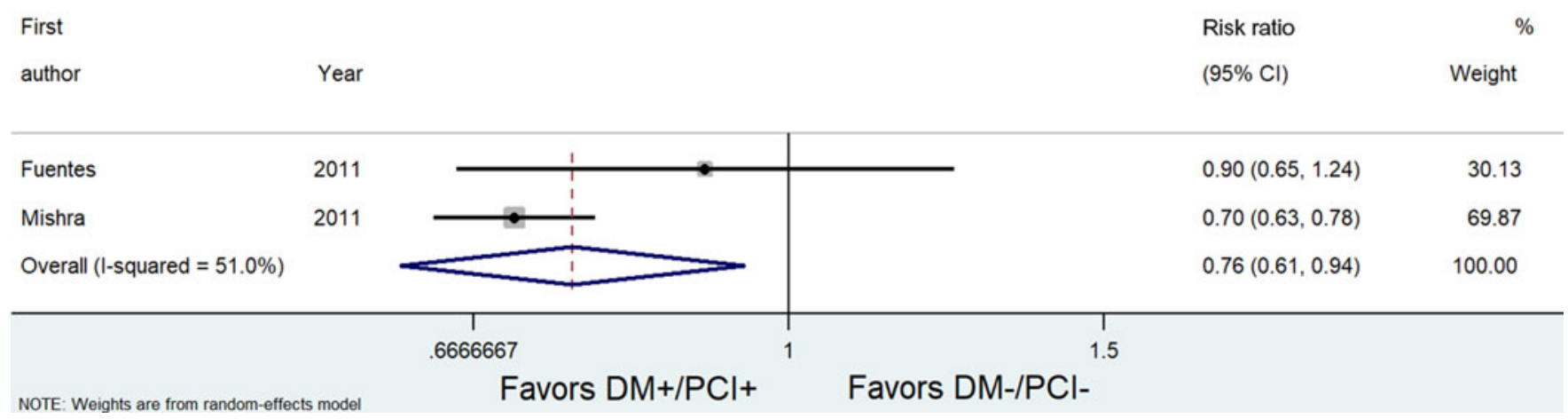

Figure 4: Forest plot showing odds ratios comparing the outcomes of diabetic patients with prior cerebral infarction (DM+/PCI+) versus patients with no diabetes and with no previous cerebral infarction (No DM+/PCI+) in terms of the risk of functional dependence.

We recall that this study had significantly higher baseline NIHSS (7 vs 5) in the DM+/PCI+ group. Our pooled outcomes may be significantly different if we had functional outcome data from this study.

Several possible confounding factors may have contributed to the higher mortality in the DM+/PCI+ group, namely, age, presence of significant comorbidities at baseline, and raised blood glucose on admission. As previously mentioned, patients in the $\mathrm{DM}+\mathrm{PCI}+$ group were older than their counterpart, and it has been shown in studies that age can significantly affect outcome resulting in higher ratio of unfavorable results. ${ }^{6,31,33}$ Moreover, patients in the DM+/PCI+ group were more medically complex than their counterparts with higher number of significant comorbidities at baseline which may have complicated their condition further. Moreover, it has been known from the SITS-ISTR report that admission hyperglycemia is an independent predictor of poor outcome after stroke in IVtPA-treated patients. ${ }^{25,34,35}$ Noncausal explanation posits that hyperglycemia may be merely an epiphenomenon indicative of an acute response to stress apart from a previous undiagnosed DM. ${ }^{35-37}$

Despite several studies supporting findings that DM+/PCI+ patients can be successfully treated with IVtPA with favorable outcomes, ${ }^{6,38-40}$ we recommend assessment of risk-benefit ratio and careful consideration of the characteristics of patients with DM and PCI for thrombolysis in acute ischemic stroke based on the results of the pooled analyses in this review. Although IVtPA may significantly improve functional disability and appear not to increase sICH events, this intervention should not be routinely given to all patients with DM and PCI due to possible increased mortality from yet undetermined, established factors. Thus, based on the data provided in this current study, limited evidence suggests that an individualized management approach in this set of population is encouraged considering all the confounding factors that could affect patient outcomes.

This study has some inherent limitations. The results were derived from looking into databases with previously collected data; hence, validity of the results was dependent on accurate documentation of clinical data and outcomes of patients in these registries. Some relevant follow-up data were missing including data in sICH in the study by Mishra. ${ }^{32}$ Finally, some results were difficult to combine due to differences in the reported outcome measures, e.g., variability in categorization of good and poor functional outcome, differences regarding timing of assessment of outcomes post-thrombolysis.

In line with this, performance of longitudinal, prospective, controlled studies may be imperative to provide a more conclusive evidence regarding the effectiveness and safety of IVtPA in patients with DM and PCI in acute ischemic stroke. In order to drive the performance of a sound and ethical clinical trial involving this subgroup of patients, provisions to demonstrate clinical equipoise, e.g., in terms of the characteristics of the participants that must be involved that could potentially benefit from this intervention, should be established. Based on the baseline characteristics of patients included in this review, younger patients with no other significant comorbidities are speculated to benefit from this intervention with no probable significant increase in sICH, and more importantly, in mortality. Another option to provide evidentiary support on the use of IVtPA in this population would be to conduct studies which were prospectively collected in countries wherein the presence of DM and PCI is not among the exclusion criteria to thrombolyze. ${ }^{32}$ Finally, interaction of different confounding factors that could possibly affect the outcome, such as stroke severity at onset as well as other medical conditions, may be analyzed in the future studies to evaluate predictors of outcomes in these patients.

\section{Conclusion}

In conclusion, limited evidence suggests that for patients who had an acute ischemic stroke within the 3-4.5 h period, diabetic patients with PCI showed no significant difference in terms of sICH compared to patients with no diabetes and PCI. Significantly more thrombolyzed diabetic patients with PCI were functionally independent at 3 months but also had higher mortality compared with patients with No DM and PCI. The decision to thrombolyze this subpopulation should be individualized with careful considerations on advanced age and significant comorbidities as to hypertension and atrial fibrillation. Further prospective, controlled studies may be necessary to substantiate the effectiveness and safety of this intervention in this subgroup population.

\section{ACKNOWLEDGMENTS}

We acknowledge the support and encouragement received from our family and loved ones and from all of those who give us inspiration. 


\section{CONFLICT OF INTEREST}

None.

\section{Statement of Authorship}

ATP: Conceptualization, data curation, formal analysis, writingoriginal draft, writing-review, and editing. JDBD: Conceptualization, data curation, formal analysis, writing-original draft, writing-review, and editing. AIE: Conceptualization, data curation, formal analysis, writing-original draft, writing-review, and editing. RJCS: Conceptualization, data curation, formal analysis, writingoriginal draft, and writing-review. AAD, AE-M, and JS: Analysis and interpretation of data, drafting, or revising the article. MACB and MCZSJ: Conceptualization, formal analysis, writing-original draft.

\section{Supplementary Material}

To view supplementary material for this article, please visit https://doi.org/10.1017/cjn.2020.63.

\section{REFERENCES}

1. Katan M, Luft A. Global burden of stroke. Semin Neurol. 2018; 38(02):208-11.

2. Campbell BCV, Meretoja A, Donnan GA, Davis SM. Twenty-year history of the evolution of stroke thrombolysis with intravenous alteplase to reduce long-term disability. Stroke. 2015;46(8):2341-6.

3. The National Institute of Neurological Disorders and Stroke rt-PA Stroke Study. Tissue plasminogen activator for acute ischemic stroke. New England J Med. 1995;333(24):1581-8.

4. Emberson J, Lees KR, Lyden P, et al. Effect of treatment delay, age, and stroke severity on the effects of intravenous thrombolysis with alteplase for acute ischaemic stroke: a meta-analysis of individual patient data from randomised trials. Lancet. 2014; 384(9958):1929-35.

5. Lahr MMH, Luijckx G-J, Vroomen PCAJ, van der Zee D-J, Buskens E. Proportion of patients treated with thrombolysis in a centralized versus a decentralized acute stroke care setting. Stroke. 2012;43(5):1336-40.

6. Karlinski M, Kobayashi A, Mikulik R, Sanak D, Wahlgren N, Czlonkowska A. Intravenous alteplase in ischemic stroke patients not fully adhering to the current drug license in central and eastern Europe. Int J Stroke. 2012;7(8):615-22.

7. Fugate JE, Rabinstein AA. Absolute and relative contraindications to IV rt-PA for acute ischemic stroke. Neurohospitalist. 2015;5(3):110-21.

8. Cronin CA, Sheth KN, Zhao X, et al. Adherence to third European Cooperative Acute Stroke Study 3- to 4.5-hour exclusions and association with outcome. Stroke. 2014;45(9):2745-9.

9. Rubiera M, Ribo M, Santamarina E, et al. Is it time to reassess the SITS-MOST criteria for thrombolysis? Stroke. 2009;40(7):2568-71.

10. Schurr A. Bench-to-bedside review: a possible resolution of the glucose paradox of cerebral ischemia. Crit Care (London, England). 2002;6(4):330-4.

11. Kruyt ND, Biessels GJ, DeVries JH, Roos YB. Hyperglycemia in acute ischemic stroke: pathophysiology and clinical management. Nature Rev Neurol. 2010;6(3):145-55.

12. Martini SR, Kent TA. Hyperglycemia in acute ischemic stroke: a vascular perspective. J Cereb Blood Flow Metab. 2007;27(3): 435-51.

13. Guidelines for management of ischaemic stroke and transient ischaemic attack 2008. Cerebrovascular Dis. 2008;25(5):457-507.

14. Hillen T, Coshall C, Tilling K, Rudd AG, McGovern R, Wolfe CDA. Cause of stroke recurrence is multifactorial. Stroke. 2003;34(6): 1457-63.

15. Lees KR, Walters MR. Acute stroke and diabetes. Cerebrovascular Dis. 2005;20(1):9-14.

16. Cappellari M, Moretto G, Micheletti N, et al. Off-label thrombolysis versus full adherence to the current European Alteplase license: impact on early clinical outcomes after acute ischemic stroke. J Thrombosis Thrombolysis. 2014;37(4):549-56.

17. Ignacio KHD, Diestro JDB, Espiritu AI, Spears J, San Jose MCZ. Re-examining the exclusion criterion of early recurrent ischemic stroke in intravenous thrombolysis: a meta-analysis. J Neurol Sci. 2020;412:116709.

18. Sarmiento RJC, Diestro JDB, Espiritu AI, San Jose MCZ. Safety and efficacy of repeated thrombolysis with Alteplase in early recurrent ischemic stroke: a systematic review. J Stroke Cerebrovascular Dis. 2019;28(10): 104290.

19. Ehrlich ME, Liang L, Xu H, et al. Intravenous tissue-type plasminogen activator in acute ischemic stroke patients with history of stroke plus diabetes mellitus. Stroke. 2019;50(6):1497-503.

20. Nordt TK, Klassen KJ, Schneider DJ, Sobel BE. Augmentation of synthesis of plasminogen activator inhibitor type- 1 in arterial endothelial cells by glucose and its implications for local fibrinolysis. Arteriosclerosis Thrombosis J Vascular Biol. 1993;13(12):1822-8.

21. Pandolfi A, Cetrullo D, Polishuck R, et al. Plasminogen activator inhibitor type 1 is increased in the arterial wall of type II diabetic subjects. Arteriosclerosis Thrombosis Vascular Biol. 2001;21(8): 1378-82.

22. Lau LH, Lew J, Borschmann K, Thijs V, Ekinci EI. Prevalence of diabetes and its effects on stroke outcomes: a meta-analysis and literature review. J Diabetes Invest. 2019;10(3):780-92.

23. Wu C, Wu D, Chen J, Li C, Ji X. Why not intravenous thrombolysis in patients with recurrent stroke within 3 months? Aging Dis. 2018;9(2):309.

24. Powers WJ, Rabinstein AA, Ackerson T, et al. Guidelines for the early management of patients with acute ischemic stroke: a guideline for healthcare professionals from the American Heart Association/ American Stroke Association. Stroke. 2018;49(3):e46-e99.

25. Filipov Alexandra EAN-PEAA. The burden of diabetes and the chance of a previous stroke: thrombolysis for recurrent stroke in diabetics. J Stroke Cerebrovascular Dis. 2018;27(5):1343-9.

26. Liberati A, Altman DG, Tetzlaff J, et al. The PRISMA statement for reporting systematic reviews and meta-analyses of studies that evaluate healthcare interventions: explanation and elaboration. BMJ. 2009;339:b2700-b.

27. Stroup DF, Berlin JA, Morton SC, et al. Meta-analysis of observational studies in epidemiology: a proposal for reporting. JAMA. 2000;283(15):2008-12.

28. Wells GA, Shea B, Connell DO, et al. The Newcastle-Ottawa Scale (NOS) for assessing the quality of nonrandomised studies in meta-analyses - Scale; 2000

29. Higgins J, Green S. Cochrane handbook for systematic reviews of interventions. Hoboken, NJ: John Wiley \& Sons; 2009.

30. Higgins JPT, Thompson SG, Deeks JJ, Altman DG. Measuring inconsistency in meta-analyses. BMJ. 2003;327(7414):557-60.

31. Fuentes B, Martínez-Sánchez P, Alonso de Leciñana M, et al. Diabetes and previous stroke: hazards for intravenous thrombolysis? European J Neurol. 2012;19(4):587-93.

32. Mishra NK, Ahmed N, Davalos A, et al. Thrombolysis outcomes in acute ischemic stroke patients with prior stroke and diabetes mellitus. Neurology. 2011;77(21):1866-72.

33. Sagnier S, Galli P, Poli M, et al. The impact of intravenous thrombolysis on outcome of patients with acute ischemic stroke after 90 years old. BMC Geriatrics. 2016;16(1):156.

34. Desilles J-P, Meseguer E, Labreuche J, et al. Diabetes mellitus, admission glucose, and outcomes after stroke thrombolysis. Stroke. 2013;44(7):1915-23.

35. Miedema I, Luijckx G-J, Brouns R, De Keyser J, Uyttenboogaart M. Admission hyperglycemia and outcome after intravenous thrombolysis: is there a difference among the stroke-subtypes? BMC Neurol. 2016;16(1):104.

36. Poppe AY, Majumdar SR, Jeerakathil T, Ghali W, Buchan AM, Hill MD. Admission hyperglycemia predicts a worse outcome in stroke patients treated with intravenous thrombolysis. Diabetes Care. 2009;32(4):617-22.

37. Ahmed N. Association of admission blood glucose and outcome in patients treated with intravenous thrombolysis. Archives Neurol. 2010;67(9):1123. 
38. Guillan M, Alonso-Canovas A, Garcia-Caldentey J, et al. Off-label intravenous thrombolysis in acute stroke. European $\mathrm{J}$ Neurol. 2012;19(3):390-4.

39. Cronin CA, Shah N, Morovati T, Hermann LD, Sheth KN. No increased risk of symptomatic intracerebral hemorrhage after thrombolysis in patients with European Cooperative Acute
Stroke Study (ECASS) exclusion criteria. Stroke. 2012; 43(6): 1684-6.

40. Kvistad CE, Logallo N, Thomassen L, Waje-Andreassen U, Brøgger J, Naess H. Safety of off-label stroke treatment with tissue plasminogen activator. Acta Neurologica Scandinavica. 2013;128(1):48-53. 